\title{
Rating the Participation of Electricity Consumers in Demand Response Events
}

\author{
Cátia Silva, Pedro Faria, Zita Vale \\ Polytechnic of Porto \\ Porto, Portugal \\ cvcds@isep.ipp.pt; pnf@isep.ipp.pt; zav@isep.ipp.pt
}

\begin{abstract}
To successfully enable Demand Response in the energy market, the necessity for modification of the actual business models urges. The authors present innovation from previous works with a method designed to deal with the uncertainty from active consumers in Demand Response events. The proposal has three variations designed to improve the accuracy of the actual response of the consumers in the management of a local community - Basic Rate, Cost Rate and Clustering Rate Methods. The attribution of reliability rates, according to previous Demand Response events (for example, emergency events where a certain target is needed), will decide which consumers are selected for the optimal scheduling. With this, the manager entity possesses valuable information to increase profit, choosing trustworthy consumers. The methods are compared in a case study with 548 DG units and 20,310 small consumers. The results demonstrate the viability of the approach and prove that reliability rates approach is useful to deal with the uncertainty of actual response in DR events.
\end{abstract}

Index Terms-- Demand Response, Energy Markets, Aggregators, Consumers, Remuneration.

\section{INTRODUCTION}

The balance between generation and real-time consumption is one of the major issues for operators of the power system, since the large scale of energy storage systems is not yet economically viable, giving popularity to Demand Response (DR) programs [1], [2]. When fully integrated into electricity markets, DR can be very useful with load shifting, avoiding load peaks, or as a replacement for both control reserve and balancing energy. Thus, when conceiving novel business models some characteristics, such as contract duration, contract volume, reliability and time lag between trading and delivery should be respected [3]. In this way, Fang et al. [4] believe that, for a successful embrace of DR programs in the energy markets, promote the participation of small resources, finding innovative solutions to reduce the uncertainty coming from the small consumer will be crucial. Their work proves that DR is profitable in regulated power markets, but its usage depends on the specific market environment. Given this, knowing the consumers is essential, according to [5]. Thus, business models should incorporate

This work has received funding from the European Union's Horizon 2020 research and innovation programme under project DOMINOES (grant agreement No 771066), from FEDER Funds through COMPETE program and from National Funds through (FCT) under the projects UIDB/00760/2020, COLORS (PTDC/EEI-EEE/28967/2017), CEECIND/02887/2017, and SFRH/BD/144200/2019, and from ANI (project GREEDi). adequate tools like artificial intelligence algorithms, big data analytics, behavioural economics approaches, socio-economic research and optimization tools, to be successful [6].

In this paper, the authors seek for ways to improve the accuracy in DR events. Being the continuity of previous works, [7], [8], where the authors proposed a solution to optimally manage a local community, the present paper is a step forward dealing with the uncertainty of the response in DR events, assigning reliability rates to each participant. From literature analysis [9], [10], several works approach the accurate prediction of aggregated demand but lack the treatment in situations of below or non-response in DR events and how the Aggregator should react in such cases. The proposed method includes a DR target to be achieved in this kind of events. For the proposed approach, the aggregator considers DR contracts with differentiated prices, where the amount of power reduction and the remuneration price are provided by the consumers. With this information, optimal scheduling of the resources is done, aiming to the minimization of the operation costs, and considering a linear approach. The nobility in this approach regarding previous works is noticed in the attribution of the Reliability Rate: only consumers with rates higher than the denominated minimum are selected for the DR event to achieve the target reduction in a more efficient way. If the first stage of scheduling is not successful on this task, a re-scheduling is performed considering the remaining consumers participating in DR programs. Achieving the reduction goal, the final stage consists of the update of Reliability Rate and Remuneration. In the present paper, the focus of the study is the comparison of the three variants of the proposed method - Basic Rate, Cost Rate and Clustering Rate Methods, for two consecutive event days in the same period. Section I introduces the topic addressed.

Section II presents a detailed explanation of the proposed methods. Section III presents assumptions for the case study as well as the community selected to prove the feasibility of the methodology and presented the results in Section IV. Finally, Section V presents the conclusions drawn from the study. 


\section{METHODS}

Fig. 1 represents the interaction model in the energy market between the several players and emphasizes the Aggregator, the main character of this work. Managing local communities, the uncertainty associated with the small resources is one of the more complex tasks of the paradigm introduced with Smart Grids. An aggregator, to properly manage the respective local market, needs to enter the wholesale market to supply the consumption or sell the generation excess. Also, introducing DR programs, different types of flexibility means can be provided. So, active consumers react to signals given in DR events providing flexibility and the aggregator remunerate them according to their response.

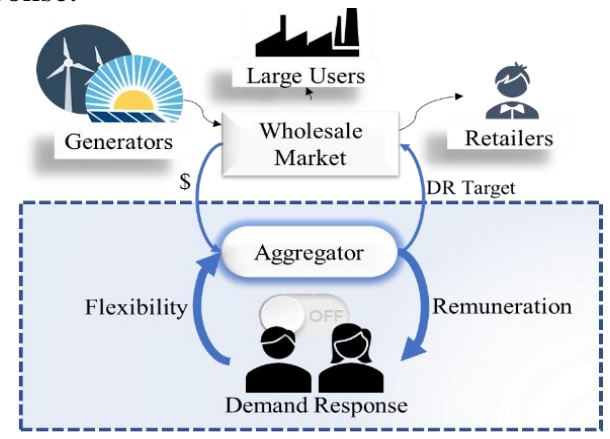

Figure 1. Interaction Model with Energy Market

The proposed method introduces DR contracts with differentiated prices where the amount of demand and participation price is provided by the consumers, being "more" active players in the transactions. The motivation behind the presented approach refers to the empowerment of small consumers in the energy market. Considering as a complex problem to be faced, the authors have as objective simulate scenarios and develop a method suitable to deal with and successfully manage the local markets. For every period, transactions are evaluated by the Aggregator considering the reliability of each resource in a DR event through an optimal Scheduling (Eq. 1). Previous information on the consumer is essential for this approach. Reliability Rate starts in 0 when no information is provided and fluctuates according to the response. The Reliability Rate depends on three different performances: Previous information (RatingHist), Actual Reduction (RatingCut) and from the last DR event (RatingLastDay).

\section{A. Designed Rates}

In the Basic Rate Method, each consumer is classified according to their response - reliability rate. Only providers with values higher than the nominated minimum are selected to be scheduled (with the optimization model presented in the following subsection). A DR target is defined and in the case of not achieving in a first schedule, a re-schedule is made. In this second phase, all the remain consumers are selected. For Cost Rate Method, a feature is added: the price fluctuates according to the actual response of the consumer. The final variation of the method is formulated based on clustering -
Clustering Rate Method. Each Reliability Rate group above the minimum is clustered using the known clustering method $\mathrm{k}$-means. The group from each rate with the higher sum of contracted reduction follows to the next phase. The remaining process stays the same.

\section{B. Optimization Model}

The small resources resident in the local community, namely, consumers participating in DR programs $\left(\mathrm{P}_{\mathrm{DR}}\right), \mathrm{DG}$ units $\left(\mathrm{P}_{\mathrm{DG}}\right)$ and even the joint of these two concepts - the prosumers, are scheduled through an optimization model. Due to the uncertainty associated with DG technologies, the connection of the resources to the larger power system is also applied through external suppliers. Two types were studied: regular ( $\mathrm{P}_{\text {SUPR }}$ ) and additional ( $\mathrm{P}_{\text {SUPA }}$ ), considering the quantities contracted at distinct prices. The additional supplier is only used in extreme cases being more expensive. Let $p$ be the number of DG units, $c$ the number of consumers, $s r$ the number of regular suppliers, sa the number of additional suppliers and $t$ the actual period. The objective function is given by Eq. 1 attributing a cost to each parameter. The first constraint is presented in Eq. 2 and represents the network balance. With this constraint, it is possible to find an equilibrium between consumption and production where the sum of the requested reduction to the consumer initial load ( $\left.\mathrm{P}_{\text {initialLoad }}\right)$ should equal the total generation from DG units and external suppliers. In the extreme eventuality of demand not met by generation means, the variable from Non-Supplied Power $\left(\mathrm{P}_{\mathrm{NSP}}\right)$ was added. The network is being well managed if the parameter $\mathrm{P}_{\mathrm{NSP}}$ is zero. The remaining constraints are presented between Eq.3 and Eq. 12.

$$
\begin{aligned}
& \text { Min. } O F=\sum\left[P_{D G}(p, t) C_{D G}(p, t)\right]+\sum\left[P_{D R}(c, t)\right. \\
& \left.C_{D R}(c, t)\right]+\sum\left[P_{S U P A}(s a, t) C_{S U P A}(s a, t)\right]+ \\
& \sum\left[P_{S U P R}(s r, t) C_{S U P R}(s r, t)\right]+P_{N S P}(t) C_{N S P}(t) \\
& \text { subject to: } \\
& \sum\left[P^{\text {initial }}(c, t)-P_{D R}(c, t)\right]=\sum\left[P_{D G}(p, t)\right]+ \\
& P_{D R}(c, t) \leq P_{I D R} \operatorname{Max}(c, t) \\
& \sum\left[P_{D R}(c, t)\right] \leq D R_{\text {target }}{ }^{M a x}(c, t) \\
& \sum\left[P_{D R}(c, t)\right] \geq D R_{\text {target }}^{\text {Min }}(c, t) \\
& P_{D G}(p, t) \leq P_{D G}{ }^{\operatorname{Max}}(p, t) \\
& P_{D G}(p, t) \geq P_{D G}{ }^{\operatorname{Min}}(p, t) \\
& \sum\left[P_{D G}(p, t)\right] \leq P_{D G}^{\text {Total }}(t) \\
& . P_{\text {SUPR }}(s r, t) \leq P_{\text {SUPR }}{ }^{\operatorname{Max}}(s r, t) \\
& \sum\left[P_{\text {SUPR }}(s r, t) \leq P_{\text {SUPR }}{ }^{\text {Total }}(t)\right. \\
& P_{S U P A}(s a, t) \leq P_{S U P A}{ }^{\operatorname{Max}}(s a, t) \\
& \sum\left[P_{S U P A}(s a, t)\right] \leq P_{S U P A}{ }^{\text {Total }}(t)
\end{aligned}
$$

Regarding the constraints related to the consumers, namely, the ones belonging to DR programs. In Eq. 3, the restriction for the maximum value of reduction for each consumer is presented as well as the DR target for the casualty of a DR event. The reason behind Eq. 4 and Eq. 5 in the model, upper and lower bound respectively, is to prevent cases when the total amount of contracted reduction is different than 
DR target. Eq. 6 to Eq. 7 refer to DG units restricting upper, lower bounds and a total maximum value of generation for these technologies giving the managing entity some control. Eq. 9 to Eq. 12 refer to External Suppliers constraining them superiorly and total amount: for regular the Eq. 7 and Eq. 8 and for Additional suppliers the Eq. 9 and Eq. 10.

\section{CASE Study}

TABLE I presents the characterization of the small resources that compose the dataset for the case study. In the chosen scenario the information regards the year of 2018, with periods of 15 minutes so 0 is 12 am and 96 is $12 \mathrm{pm}$. Ten local communities were randomly created. And although the characterization is for the whole communities, only one is considered in the study. Previous works experience that, performing scheduling for one period, the solving time for the entire community was overly high, not pondering the remaining process.

\section{TABLE I. SMALL RESOURCES CHARACTERIZATION}

\begin{tabular}{|c|c|c|c|c|}
\hline \multirow{7}{*}{ 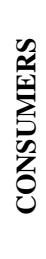 } & Type & $\begin{array}{l}\text { Number of } \\
\text { elements }\end{array}$ & $\begin{array}{c}\text { Capacity } \\
(\mathbf{k W h})\end{array}$ & $\begin{array}{l}\begin{array}{l}\text { Initial Price } \\
\text { (m.u./kWh) }\end{array} \\
\end{array}$ \\
\hline & Domestic & 10,168 & \multirow{6}{*}{$21,354.36$} & 0.12 \\
\hline & Small Commerce & 9,828 & & 0.18 \\
\hline & Medium Commerce & 82 & & 0.20 \\
\hline & Large Commerce & 85 & & 0.19 \\
\hline & Industrial & 147 & & 0.15 \\
\hline & Total & 20,310 & & \\
\hline \multirow{9}{*}{ לِ } & Type & $\begin{array}{c}\text { Number of } \\
\text { units }\end{array}$ & $\begin{array}{c}\text { Capacity } \\
\text { (kWh) }\end{array}$ & $\begin{array}{c}\text { Tariff } \\
(\mathbf{m} . \mathbf{u} . / \mathrm{kWh})\end{array}$ \\
\hline & Small Hydro & 25 & \multirow{8}{*}{$25,388.79$} & 0.0961 \\
\hline & Waste-to-energy & 7 & & 0.0900 \\
\hline & Wind & 254 & & 0.0988 \\
\hline & Photovoltaic & 208 & & 0.2889 \\
\hline & Biomass & 25 & & 0.1206 \\
\hline & Fuel Cell & 13 & & 0.0945 \\
\hline & Co-generation & 16 & & 0.0975 \\
\hline & Total & 548 & & \\
\hline
\end{tabular}

For the scenario created in this study, the community with a higher reliability rate was chosen, counting with 406 consumers and an average reliability rate of 3.10. TABLE II demonstrates the number of consumers in each reliability rate for the local community. The minimum rate to join the scheduling is Reliability Rate 3.

TABLE II. NUMBER OF ELEMENTS PER RATE BEFORE SCHEDULING

\begin{tabular}{|c|c|c|c|c|c|}
\hline Rate & 1 & 2 & 3 & 4 & 5 \\
\hline $\mathbf{N}^{\mathbf{0}}$ Elements & 215 & 68 & 66 & 43 & 14 \\
\hline
\end{tabular}

The DR event as a reduction target $100 \mathrm{~kW}$ for the scenario formed - comparison between two consecutive days in the week, Tuesday (Day D-1) and Wednesday (Day D) for the same period $-3 \mathrm{pm}$ or period 60 . For the attribution of the reliability rate for each consumer, five samples were considered from the same day and period on previous weeks. The goal is understanding the influence of the previous result rate. TABLE III shows the weights applied in the formation of the reliability rate for each stage of the proposed methods. It is also important to highlight the fact that the response from the consumers is randomly modelled.
TABLE III. WEIGHTS FOR RELIABILITY RATE OF EACH CONSUMER (RATINGCONS)

\begin{tabular}{|l|c|c|c|c|}
\cline { 2 - 5 } \multicolumn{1}{c|}{} & \multicolumn{2}{c|}{ Day D-1 } & \multicolumn{2}{c|}{ Day D } \\
\cline { 2 - 5 } \multicolumn{1}{c|}{} & Before & After & Before & After \\
\hline RatingHist & 1 & 0.60 & 1 & 0.60 \\
\hline RatingCut & - & 0.40 & - & 0.20 \\
\hline RatingLastDay & - & - & - & 0.20 \\
\hline
\end{tabular}

IV. RESULTS AND DISCUSSION

The following results charts are designed according to the reduction for both days and the necessity for a re-scheduling. A confrontation between DR Target, the requested reduction and actual reduction is done. In this way, Section A, Section B and Section $C$ present the optimization results for both days, scheduling and re-scheduling, as well as the number of elements in each Reliability Rate group for Basic Rate Method, Cost Rate Method and Clustering Rate Method, respectively.

\section{A. Basic Rate Method}

The Basic Rate Method considers consumers with Reliability rate above 3 for scheduling. Fig. 2 presents the optimization results in both Days (D-1) and (D).

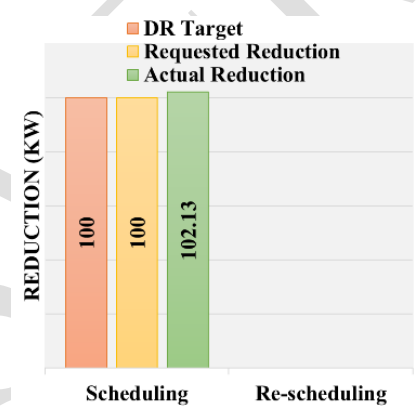

(a)

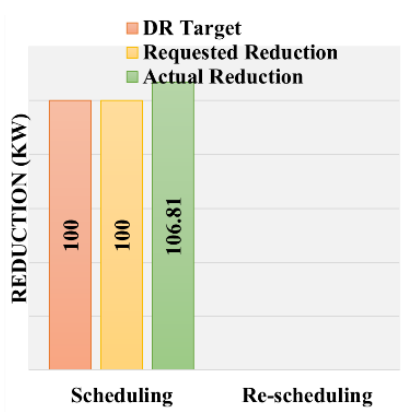

(b)
Figure 2. Optimization Results (a) Day D-1; (b) Day D

For the two days, the requested reduction for the chosen consumers equals the DR Target and the actual reduction was always higher, namely, $102.13 \mathrm{~kW}$ for Day (D-1) and 106.8 $\mathrm{kW}$ for Day (D). The efficacy of the approach was proven in this period being able to nominate the appropriate consumers. TABLE IV presents the number of elements per reliability rate after scheduling.

TABLE IV. NUMBER OF ELEMENTS PER RATE FOR BASIC RATE METHOD

\begin{tabular}{|c|l|c|c|c|c|c|}
\hline \multicolumn{2}{|c|}{ Rate } & 1 & 2 & 3 & 4 & 5 \\
\hline \multirow{3}{*}{$\begin{array}{c}N^{\circ} \\
\text { Elements }\end{array}$} & $(\mathrm{D}-1)-$ After & 215 & 100 & 40 & 44 & 7 \\
\cline { 2 - 7 } & $(\mathrm{D})-$ Before & 215 & 68 & 66 & 43 & 14 \\
\cline { 2 - 7 } & $(\mathrm{D})-$ After & 215 & 68 & 90 & 19 & 14 \\
\hline
\end{tabular}

When the weight of the RatingCut represents a higher percentage in the final rate of the consumer, a higher number of elements tend to lower their rate. One of the examples of this event is Day (D-1) after scheduling. Regarding Day (D), where RatingCut weight was lower but the RatingLastDay also has considerable value, the number of elements that decreased their reliability rate was smaller.

\section{B. Cost Rate Method}

Cost Rate Method beyond considering the reliability rate also fluctuate the price to increase the hypophysis of lower 
rate consumers being chosen in the minimization problem. Fig. 3 details the results for the present method for Day (D-1) and Day (D).

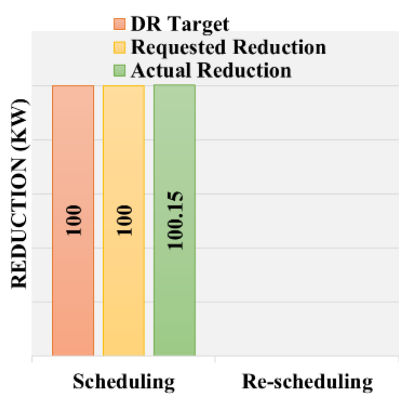

(a)

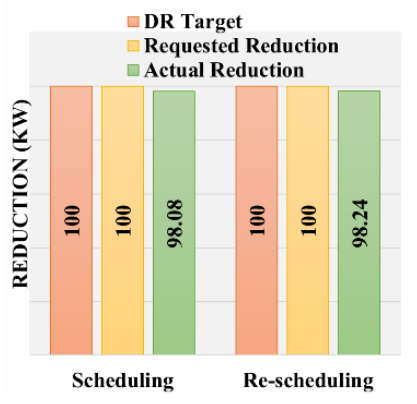

(b)
Figure 3. Optimization Results (a) Day D-1; (b) Day D.

The motivation for this method lies on the facilitation on the climb in the reliability rate considering that consumer wants to participate in the event - allied with a higher reduction than the requested, and fluctuation on proposed remuneration price. In Day (D-1), although with a close result, the amount of actual reduction was sufficient to reduce the DR Target requested. The same situation was not conceivable in Day (D) since the actual reduction in the scheduling was lower than the requested reduction $-98.08 \mathrm{~kW}$. In this way, a rescheduling was done resulting in a similar solution. Although the number of participants was higher, the actual reduction was not enough. The participants added belonged to lower rates. Once the prices from the previous days were considered (lower prices), the minimization opt for them. Given this opportunity, to increase the rate, the logic action was to reduce the requested, but their response was not satisfactory. Allied to this fact, the results presented in TABLE V show some decrease in performance of higher rates. Focusing on the results for reliability rate 4 , the number of elements decreased from 43 to 19. Even though RatingCut has a lower weight, the response from these consumers was far from the expected.

TABLE V. Number of ELEMENTS PER RATE FOR COST RATE METHOD

\begin{tabular}{|c|l|c|c|c|c|c|}
\hline \multicolumn{2}{|c|}{ Rate } & 1 & 2 & 3 & 4 & 5 \\
\hline \multirow{3}{*}{$\begin{array}{c}\mathbf{N}^{\mathbf{o}} \\
\text { Elements }\end{array}$} & (D-1) - After & 215 & 98 & 40 & 46 & 7 \\
\cline { 2 - 7 } & (D) - Before & 215 & 68 & 66 & 43 & 14 \\
\cline { 2 - 7 } & (D) - After & 215 & 68 & 90 & 19 & 14 \\
\hline
\end{tabular}

To understand the result for Cost Rate Method, the authors opted to study deeper and select several consumer responses and how their performance affects their reliability rate. In this way, a comparison between the actual response and the requested reduction was done. Results were classified by SAME when the amount of requested reduction is equal to the actual reduction; LOWER when the amount of requested reduction is lower to the actual reduction and HIGHER when the amount of requested reduction is higher to the actual reduction. TABLE VI presents the results for Day (D-1), namely the number of elements per classification and the amount of reduction. Also, the total requested participants and the actual, considering that can be requested but no response was given.
TABLE VI. Global Results For Cost RAte Method (D-1)

\begin{tabular}{|l|c|c|c|c|c|}
\cline { 2 - 6 } \multicolumn{1}{c|}{} & SAME & LOWER & HIGHER & $\begin{array}{c}\text { Requested } \\
\text { Participants }\end{array}$ & $\begin{array}{c}\text { Actual } \\
\text { Participants }\end{array}$ \\
\hline \# Elements & 344 & 31 & 31 & 62 & 62 \\
\hline Reduction (kW) & 0.00 & 41.87 & 58.27 & \multicolumn{2}{c|}{100.15} \\
\hline
\end{tabular}

The high number of elements are in the SAME group, being these the non-requested consumers with the reduction of $0 \mathrm{~kW}$. Regarding the remaining groups, both with 31 elements, the agglomerate reduction from HIGHER was enough to compensate the LOWER group, summing a total of $100.15 \mathrm{~kW}$ of reduction in the period between 60 and 61 . Five consumers were selected to understand the influence of their performance in the final rate, as shown in TABLE VII. Consumers 1, 4 and 5 were not selected for the reduction. Consumer 2 was selected and exceeds the requested reduction increasing his final rate. Although the response from Consumer 3 was lower, it was not enough to decrease his reliability rate. Following Day (D), the global results are presented in TABLE VIII.

TABLE VII. Selected Consumers' Performance Day (D-1)

\begin{tabular}{|c|c|c|c|c|c|}
\hline ID & $\begin{array}{c}\text { Requested } \\
\text { Reduction }\end{array}$ & $\begin{array}{c}\text { Actual } \\
\text { Reduction }\end{array}$ & $\begin{array}{c}\text { Initial } \\
\text { Rate }\end{array}$ & Performance & Final Rate \\
\hline 1 & 0.00 & 0.00 & 1 & SAME & SAME (1) \\
\hline 2 & 1.39 & 1.83 & 3 & HIGHER & HIGHER (4) \\
\hline 3 & 0.77 & 0.71 & 4 & LOWER & SAME (4) \\
\hline 4 & 0.00 & 0.00 & 2 & SAME & SAME (2) \\
\hline 5 & 0.00 & 0.00 & 2 & SAME & SAME (2) \\
\hline
\end{tabular}

TABLE VIII. GLOBAL RESUlts FOR COST RATE METHOD (D)

\begin{tabular}{|l|c|c|c|c|c|}
\cline { 2 - 6 } \multicolumn{1}{c|}{} & SAME & LOWER & HIGHER & $\begin{array}{c}\text { Requested } \\
\text { Participants }\end{array}$ & $\begin{array}{c}\text { Actual } \\
\text { Participants }\end{array}$ \\
\hline \# Elements & 387 & 9 & 10 & 57 & 56 \\
\hline Reduction $(\mathrm{kW})$ & 71.79 & 15.43 & 11.01 & \multicolumn{3}{c|}{98.24} \\
\hline
\end{tabular}

In this situation, the model requested 57 participants, supposedly enough to supply the difference between scheduling and re-scheduling (Fig.3). However, their performance was not as expected: one of them did not respond (Consumer 4) and 26 consumers responded with lower than the requested reduction. In this case, the HIGHER group was not able to achieve the DR Target. TABLE IX shows the results for the same consumers for Day (D-1). The actual response from Consumer 4, whose reliability rate is higher and expected to be the consumers with responses more reliable, responded with lower than requested. Still, none of the consumers decreases their level due to the lower weight of RatingCut in Day (D). From this study, it can be deduced the amount of remuneration is crucial to reduce the uncertainty of the response. Fluctuating to lower prices can mean a selection to participate, but remuneration may not be enough to pay for the discomfort or bring benefit for the consumer.

TABle IX. SElected Consumers' Performance Day 2

\begin{tabular}{|c|c|c|c|c|c|}
\hline ID & $\begin{array}{c}\text { Requested } \\
\text { Reduction }\end{array}$ & $\begin{array}{c}\text { Actual } \\
\text { Reduction }\end{array}$ & $\begin{array}{c}\text { Initial } \\
\text { Rate }\end{array}$ & Performance & Final Rate \\
\hline 1 & 0.00 & 0.00 & 1 & SAME & SAME (1) \\
\hline 2 & 0.00 & 0.00 & 3 & SAME & SAME (3) \\
\hline 3 & 0.77 & 0.62 & 4 & LOWER & SAME (4) \\
\hline 4 & 0.31 & 0.00 & 2 & LOWER & SAME (2) \\
\hline 5 & 1.61 & 0.15 & 2 & LOWER & SAME (2) \\
\hline
\end{tabular}




\section{Clustering Rate Method}

Resorting to k-means, the elements in each reliability rate are clustered to extract the group of consumers with a higher amount of reduction for the first phase. Fig. 4 shows the optimization results gathered in this method. As in the remain methods, for the Day (D-1), the scheduled consumers were reliable enough to surpass the DR target. In Day (D), the sum of the $\mathrm{P}^{\max }{ }_{\mathrm{DR}}$ from the selected groups in the clustering is lower than the DR target, so it is immediately concluded the need for a re-scheduling in this case. In this way, one of the flaws in this method is the case where the higher reliability rates have a low number of elements with low contracted power reductions for DR events.

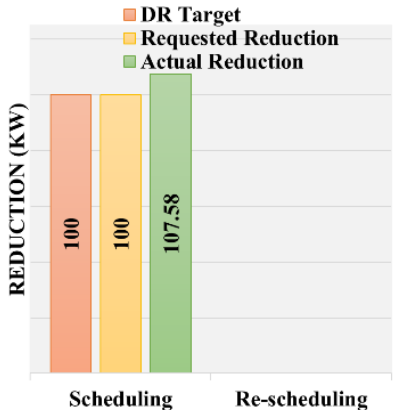

(a)

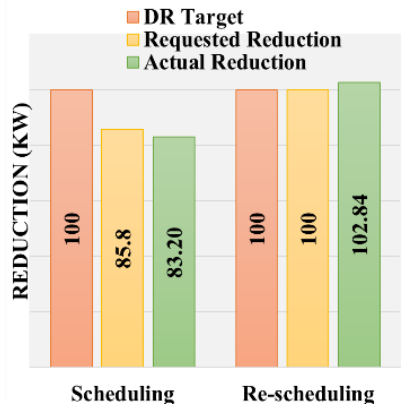

(b)
Figure 4. Optimization Results (a) Day D-1; (b) Day D

When all the consumers were included, the requested reduction equal the DR target and the actual reduction was higher than $100 \mathrm{~kW}$, resulting in $102.84 \mathrm{~kW}$. TABLE X, like previous methods, present the number of elements per rate and the total remuneration for the studied Days. In this method, the greatest differences were noticed regarding the number of elements, even with the Day (D) before scheduling which so far had been the same in previous cases. For the first time, the elements in the reliability rate 1 decreased when comparing before and after scheduling.

TABLE X. Number of ELEMENTS PER RATE FOR COST RATE METHOD

\begin{tabular}{|c|l|c|c|c|c|c|}
\hline \multicolumn{2}{|c|}{ Rate } & 1 & 2 & 3 & 4 & 5 \\
\hline \multirow{2}{*}{$\begin{array}{c}\mathbf{N}^{\mathbf{0}} \\
\text { Elements }\end{array}$} & (D-1)-After & 215 & 106 & 42 & 40 & 3 \\
\cline { 2 - 7 } & (D)-Before & 222 & 77 & 66 & 33 & 8 \\
\cline { 2 - 7 } & (D)-After & 213 & 108 & 59 & 23 & 3 \\
\hline
\end{tabular}

\section{Remuneration}

Given the importance of the Remuneration phase for both intervenient, a comparison between the remuneration of methods is done and presented in TABLE XI. Underlining the results from Cost Rate Method, Day (D) has the lower value but the target was not achieved. The authors must find ways to penalize this type of behaviour. Also, compensate values above the referred target may prejudice the Aggregator.

TABLE XI. FINAL REMUNERATION

\begin{tabular}{|c|c|c|}
\hline \multirow{2}{*}{ Method } & \multicolumn{2}{|c|}{ Remuneration (m.u.) } \\
\cline { 2 - 3 } & Day (D-1) & Day (D) \\
\hline Basic Rate & 20.58 & 21.52 \\
\hline Cost Rate & 20.35 & 19.00 \\
\hline Clustering Rate & 21.68 & 20.88 \\
\hline
\end{tabular}

\section{CONCLUSIONS}

The present paper introduces a comparison of three different variations of a method designed to deal with the uncertainty of consumers' response to DR events, being a step forward from previous works. Through the discussion of the results, it was possible to extract some conclusions regarding the consumer behaviour: when fluctuating the remuneration price for participating in DR events, namely with Cost Rate Method, the willingness to reduce the requested amount was lower (sometimes, the Aggregator was not able to achieve the target with only one re-scheduling). The residential sector prioritizes comfort while the industrial focus on the maximization of the benefit. When the incentive is not enough, the disposition to exchange their goal for the participation decreases. Although in the study presented the consumers were the ones proposing their reduction price, it is visible the necessity for a tool able to meet all the constraints optimally. Being advantageous not only for the demand side but also for the manager, improving reliability. As future works, the authors want to further investigate the fluctuation of remuneration price in Cost Rate Method and study the influence of reliability rating for longer periods

\section{REFERENCES}

[1] E. Espe, V. Potdar, E. Chang, E. Espe, V. Potdar, and E. Chang, "Prosumer Communities and Relationships in Smart Grids: A Literature Review, Evolution and Future Directions," Energies, vol. 11, no. 10 , p. 2528, Sep. 2018, DOI: $10.3390 /$ en 11102528 .

[2] M. Gheydi, P. Farhadi, and R. Ghafari, "The effect of demand response on the operation of the smart home energy system with renewable energy resources,” 2016 Int. Symp. Fundam. Electr. Eng. ISFEE 2016, pp. 1-6, 2016, DOI: 10.1109/ISFEE.2016.7803218.

[3] S. Feuerriegel and D. Neumann, "Integration scenarios of Demand Response into electricity markets: Load shifting, financial savings and policy implications," Energy Policy, vol. 96, pp. 231-240, Sep. 2016, DOI: 10.1016/J.ENPOL.2016.05.050.

[4] C. Fang, B. Fan, T. Sun, D. Feng, and J. Chen, "Business models for demand response aggregators under regulated power markets," CIRED - Open Access Proc. J., vol. 2017, no. 1, pp. 1614-1617, 2017, DOI: 10.1049/oap-cired.2017.1023.

[5] I. Ilieva, B. Bremdal, and S. Puranik, "Bringing Business and Societal Impact Together in an Evolving Energy Sector," Clean Energy Technol., vol. 7, no. 3, 2019, DOI: 10.18178/jocet.2019.7.3.508.

[6] P. Makris et al., "Digitization era for electric utilities: A novel business model through an inter-disciplinary $\mathrm{s} / \mathrm{w}$ platform and open research challenges," IEEE Access, vol. 6, no. April, pp. 22452-22463, 2018, DOI: 10.1109/ACCESS.2018.2828323.

[7] C. Silva, P. Faria, and Z. Vale, "Demand response and distributed generation remuneration approach considering planning and operation stages," Energies, vol. 12, no. 14, p. 2721, 2019, DOI: 10.3390/en12142722.

[8] C. Silva, P. Faria, and Z. Vale, "Study of Multi-Tariff Influence on the Distributed Generation Remuneration," in 16th International Conference Distributed Computing and Artificial Intelligence, 2020, pp. 14-19, DOI: 10.1007/978-3-030-23946-6_2.

[9] B. Zeng, X. Wei, D. Zhao, C. Singh, and J. Zhang, "Hybrid probabilistic-possibilistic approach for capacity credit evaluation of demand response considering both exogenous and endogenous uncertainties," Appl. Energy, vol. 229, pp. 186-200, Nov. 2018, DOI: 10.1016/j.apenergy.2018.07.111.

[10] Y. Liu, B. Guo, T. Zhang, R. Wang, and Y. Zhang, "Model predictive control-based operation management for a residential microgrid with considering forecast uncertainties and demand response strategies," IET Gener. Transm. Distrib., vol. 10, no. 10, pp. 2367-2378, Jul. 2016, DOI: 10.1049/iet-gtd.2015.1127. 